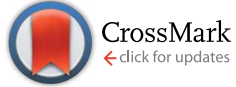

Cite this: Soft Matter, 2014, 10, 7285

Received 11th June 2014

Accepted 7th July 2014

DOI: $10.1039 / \mathrm{c} 4 \mathrm{sm} 01255 \mathrm{k}$

www.rsc.org/softmatter

\section{Dark conglomerate phases of azobenzene derived bent-core mesogens - relationships between the molecular structure and mirror symmetry breaking in soft matter $\dagger$}

\begin{abstract}
Mohamed Alaasar, ${ }^{\star a b}$ Marko Prehm, ${ }^{a}$ Marcel Brautzsch ${ }^{a}$ and Carsten Tschierske*a
New 4-bromoresorcinol based bent-core molecules with peripheral fluoro substituted azobenzene wings have been synthesized and the liquid crystalline self-assembly was investigated by differential scanning calorimetry (DSC), optical polarizing microscopy (POM), electro-optic studies and X-ray diffraction (XRD). A new type of optically isotropic mesophase composed of chiral domains with opposite handedness (dark conglomerate phases, DC phases) is observed, which for some homologues with medium alkyl chain length is stable down to ambient temperature. It is proposed that these DC phases are formed by helical twisted nano-domains of limited size and composed of the crystallized aromatic cores which are separated by the disordered alkyl chains. This structure is distinct from the previously known soft helical nano-filament phases (HNF phases, $B_{4}$ phases) formed by extended crystalline nano-filaments and also distinct from the fluid sponge phases composed of deformed fluid layers. Comparison with related bentcore molecules having $\mathrm{H}, \mathrm{F}, \mathrm{Cl}, \mathrm{I}, \mathrm{CH}_{3}$ and $\mathrm{CN}$ groups in the 4-position at the resorcinol core, either with or without additional peripheral fluorines, provided information about the effects of these substituents on the tendency to form DC phases. Based on these relationships and by comparison with the minimum energy conformations obtained by DFT calculations a hypothesis is provided for the formation of DC phases depending on the molecular structure.
\end{abstract}

\section{Introduction}

The observation of spontaneous development of macroscopic chirality in soft matter systems of achiral molecules is a contemporary research topic with great importance for the general understanding of spontaneous mirror symmetry breaking, and this might also be useful for numerous practical applications. This phenomenon is in recent years most often found in liquid crystalline phases of some molecules with an extended bent aromatic core (bent-core molecules). ${ }^{\mathbf{1}, \mathbf{2}}$ Helical superstructures in columns ${ }^{\mathbf{3}, 4}$ and self-assembly in helical filaments $^{5-9}$ represent other prominent examples of mirror symmetry breaking at the nano-scale. ${ }^{10}$ However, in these 1D organizations chiral segregation occurs only locally, along the aggregates, whereas the lateral interaction between them is only weak, so that usually no macroscopic chirality could be achieved in the absence of a chiral dopant. ${ }^{2}$ Only for achiral dibenzo $[g, p]$ chrysenes with short peripheral chains macroscopic

${ }^{a}$ Institute of Chemistry, Martin Luther University Halle-Wittenberg, Kurt Mothes Str. 2, D-06120 Halle (Saale), Germany.E-mail: carsten.tschierske@chemie.uni-halle.de

${ }^{b}$ Department of Chemistry, Faculty of Science, Cairo University, Giza, Egypt. E-mail: malaasar@sci.cu.edu.eg

$\dagger$ Electronic supplementary information (ESI) available. See DOI: $10.1039 / \mathrm{c} 4 \mathrm{sm} 01255 \mathrm{k}$ spontaneous segregation of chiral conformers was observed in a columnar phase. ${ }^{4}$ In contrast, in polar smectic LC phases of bent-core liquid crystals (BCLCs) the spontaneous formation of conglomerates of macroscopically chiral domains is more frequently observed. Here chirality emerges in layers (smectic phases) which provides a stronger coupling and therefore can more easily transfer chirality over larger distances. ${ }^{1}$ In addition, a geometric layer chirality arising from the combination of tilt and polar order in the polar smectic phases of bent-core molecules is assumed to play an important role in the development of macroscopic chirality in these smectic phases, ${ }^{\mathbf{1 1}}$ as it can couple with the molecular conformational chirality via diastereomeric interactions. On the other hand, in all cases of lamellar phases the packing of helical entities, ranging from helical conformers of single molecules via bent dimesogens to helical nano-filaments, is in competition with the formation of extended flat layers and thus leads to layer distortion. ${ }^{\mathbf{1 2}}$ In many cases this distortion is strong enough to remove the macroscopic anisotropic properties of liquid crystals, giving rise to isotropic mesophases which, due to the absence of birefringence, allow an easy identification of chirality by polarizing microscopy. These soft isotropic mesophases composed of a conglomerate of domains with opposite handedness are designated as dark conglomerate phases (DC phases). Depending on the local 
structure of these DC phases they can be classified as liquid crystalline sponge phases, ${ }^{\mathbf{1 3 - 1 9}}$ formed by strongly deformed fluid layers or as helical nanofilament phases (HNF phases, also assigned as $\mathrm{B}_{4}$ phase ${ }^{\mathbf{2 0}}$ ) having crystallized aromatic segments organized in helical nano-scale filaments which are separated by the disordered alkyl chain segments. ${ }^{21-27}$ Aside from these two known cases a number of additional DC phases with intermediate or with quite distinct nano-structures can be expected, only a few of them have very recently been observed. ${ }^{28-30}$ Moreover, conglomerates of chiral domains were also found in apolar SmC phases with only local polar domains $\left(\operatorname{SmC}_{\mathrm{S}} \mathrm{P}_{\mathrm{R}}{ }^{[*]} \text { phases }\right)^{31,32}$ and in nematic phases formed by some bent-core mesogens. ${ }^{33-35}$ In these cases of LC phases with reduced order and without long range layer chirality the formation of DC phases is also dependent on surface interactions. However, the relationships between the formation of the distinct types of DC phases and the required molecular structures are still unknown. Therefore, the search for new molecular structures capable of forming DC phases and the investigation of their general structure property relationships is of significant importance. Moreover, DC phases could represent interesting materials for a variety of applications, such as organic semiconductors, thin-film transistors and solar cells, ${ }^{36}$ as thin-film polarizers, ${ }^{37}$ as nonlinear optical materials ${ }^{38}$ as well as for the detection and amplification of chirality, ${ }^{39}$ and eventually also for separation of enantiomers and for enantioselective synthesis. ${ }^{\mathbf{4 0}}$

DC phases involving photoisomerizable azobenzene units were previously only reported for dimesogens composed of two azobenzene units connected by odd-numbered aliphatic spacers $^{\mathbf{4 1}}$ and for $\mathrm{W}$-shaped molecules. ${ }^{\mathbf{4 2}}$ Only recently, we have found that the azobenzene unit is a very useful building block for bent-core mesogens forming new types of HNF-like DC phases. ${ }^{\mathbf{4 3 4}}$ Broad regions of these DC phases have been found for 4-iodoresorcinol based ${ }^{43}$ as well as 4-methylresorcinol based bent-core mesogens with two azobenzene wings (see Scheme 1). ${ }^{44}$ In contrast, related 4-chloro and 4-fluoro substituted compounds do not form any DC phases.

Fluorine substitution at the periphery of the bent aromatic core has a significant effect on the liquid crystalline behaviour of BCLCs, ${ }^{45}$ for example it can change the switching from antiferroelectric to ferroelectric., ${ }^{\mathbf{1 4 6}}$ In the case of the azobenzene based BCLCs it affects the formation of DC phases. Whereas F-substitution is required for the formation of DC phases of 4 -iodoresorcinols with two azobenzene wings, ${ }^{43}$ it removes the DC phase in the case of the analogous 4-methyl substituted compounds (Scheme 1). ${ }^{\mathbf{4 4}}$

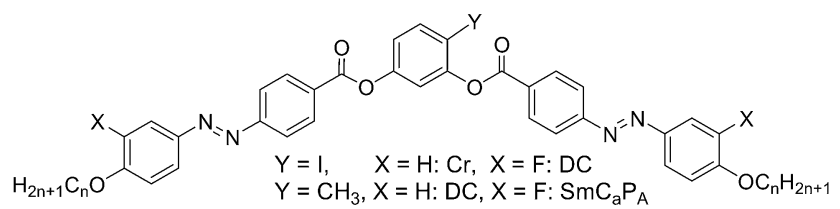

Scheme 1 Effect of fluorine substitution ( $X=F v s$. $H$ ) on the formation of DC phases in azobenzene-based BCLCs (abbreviations; $D C=$ dark conglomerate phase, $\mathrm{SmC}_{\mathrm{a}} \mathrm{P}_{\mathrm{A}}=$ anticlinic tilted antiferroelectric switching SmC phase, $\mathrm{Cr}=$ crystalline solid) ${ }^{43,44}$
Here we report a new class of DC phase forming BCLCs based on 4-bromoresorcinol and having additional fluorine atoms at the periphery of the attached azobenzene wings, adjacent to the terminal alkyl chains. These compounds are compared with related compounds with $\mathrm{F}, \mathrm{Cl}, \mathrm{I}, \mathrm{CH}_{3}$ and $\mathrm{CN}$ substituents in the 4-position at the resorcinol core, either with or without additional peripheral fluorine substitution..$^{31,32,43,44,47,48}$ The designation of the molecules reported herein follows the general notation YXn , where Y indicates the 4-substituent at the resorcinol core, $\mathrm{X}=\mathrm{F}$ indicates the presence of peripheral fluorines, the absence of $\mathrm{X}$ indicates a non-fluorinated compound where $\mathrm{X}=\mathrm{H}$ and $n$ gives the alkyl chain length (see Scheme 1). Besides the series of 4-bromoresorcinol compounds BrFn also some additional compounds (HF12, FF12, ClF12, MF12, IF16) required for proper comparisons were newly synthesized. DFT calculations provide information about the effects of the different substituents Y on the minimum energy conformations, which is related to the experimentally determined tendency to form DC phases of different types. A hypothesis is provided for the prediction of formation of DC phase depending on the molecular structure.

\section{Experimental}

\subsection{Synthesis}

The synthesis of the target BCLCs BrFn was performed by acylation of 4-bromoresorcinol with two equivalents of the appropriate 4-(4- $n$-alkoxy-3-fluorophenylazo)benzoyl chloride in the presence of triethylamine as base and pyridine as acylation catalyst (Scheme 2). ${ }^{49}$ Details of synthesis of the intermediates and final compounds as well as analytical data are reported in the ESI. $\dagger$

In analogy to the synthesis of compounds BrFn also the 4-substituted resorcinol based bent-core mesogens $\mathrm{HF12}(\mathrm{X}=\mathrm{F}$, $\mathrm{Y}=\mathrm{H}), \boldsymbol{F F 1 2}(\mathrm{X}, \mathrm{Y}=\mathrm{F}), \boldsymbol{C l F 1 2}(\mathrm{X}=\mathrm{F}, \mathrm{Y}=\mathrm{Cl}), \operatorname{MF12}(\mathrm{X}=\mathrm{F}, \mathrm{Y}=$ $\left.\mathrm{CH}_{3}\right)$ and IF16 ( $\left.\mathrm{X}=\mathrm{F}, \mathrm{Y}=\mathrm{I}\right)$ have been synthesized. The analytical data and other details of these new compounds (see Table 1) are also reported in the ESI. $\dagger$

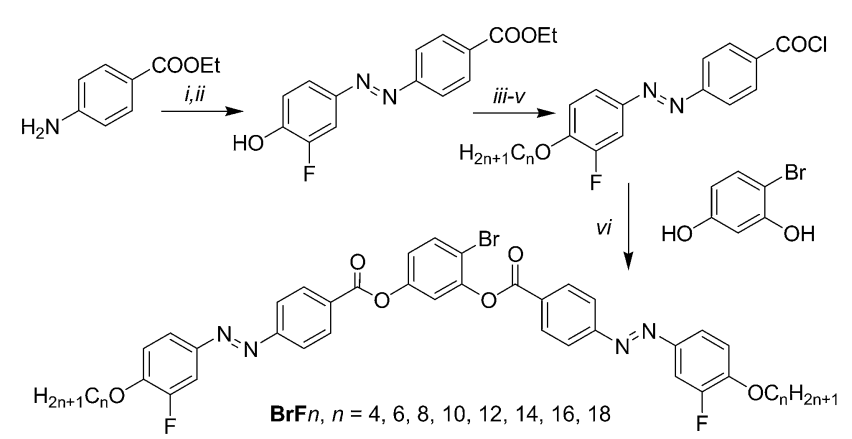

Scheme 2 Chemical structures and synthesis of compounds BrFn. Reagents and conditions: (i) $\mathrm{NaNO}_{2}, \mathrm{HCl}, \mathrm{H}_{2} \mathrm{O}, 0{ }^{\circ} \mathrm{C}, 30 \mathrm{~min}$; (ii) 1. 2fluorophenol, $\mathrm{NaOH}, 0-5{ }^{\circ} \mathrm{C}, 3 \mathrm{~h}, 2 . \mathrm{NaHCO}_{3}$; (iii) $\mathrm{C}_{n} \mathrm{H}_{2 n+1} \mathrm{Br}, \mathrm{K}_{2} \mathrm{CO}_{3}$, $\mathrm{Kl}, 2$-butanone, reflux, $18 \mathrm{~h}$; (iv) 1. $\mathrm{KOH}$, EtOH, reflux, $8 \mathrm{~h}$, (2) $\mathrm{H}^{+}$; (v) $\mathrm{SOCl}_{2}$, DMF, reflux, $1 \mathrm{~h}$; (vi) TEA, pyridine, $\mathrm{CH}_{2} \mathrm{Cl}_{2}$, reflux, $6 \mathrm{~h}$. 
Table 1 Phase transition temperatures $\left(T /{ }^{\circ} \mathrm{C}\right)$, mesophase types, and transition enthalpies $\left[\Delta H / \mathrm{kJ}^{\mathrm{mol}}{ }^{-1}\right]$ of the synthesized compounds BrFn, IF16, HF12, FF12, CIF12 and MF12 ${ }^{a}$

\begin{tabular}{|c|c|c|c|c|}
\hline BrF4 & $\mathrm{Br}$ & 4 & Cr 157 [57.7] Iso & Iso $117[50.4] \mathrm{Cr}$ \\
\hline BrF6 & $\mathrm{Br}$ & 6 & Cr 126 [45.9] Iso & Iso $96[23.8] \mathrm{DC}$ \\
\hline BrF8 & $\mathrm{Br}$ & 8 & Cr 119 [55.0] Iso & Iso 96 [25.9] DC \\
\hline BrF10 & $\mathrm{Br}$ & 10 & Cr 106 [19.0] Iso & Iso $99[25.6] \mathrm{DC}$ \\
\hline BrF12 & $\mathrm{Br}$ & 12 & Cr $106[24.6]$ Iso & Iso $98[25.7] \mathrm{DC}$ \\
\hline HF12 & $\mathrm{H}$ & 12 & $\mathrm{Cr}_{1} 81[21.2] \mathrm{Cr}_{2} 138$ [40.5] Iso & Iso $130[16.5] \mathrm{Cr}_{1} 103[34.2] \mathrm{Cr}_{2} 75[21.6] \mathrm{Cr}_{3}$ \\
\hline FF12 & $\mathrm{F}$ & 12 & Cr 120 [60.2] Iso & Iso $116[18.0] \mathrm{SmC}_{\mathrm{a}} \mathrm{P}_{\mathrm{A}}{ }^{d} 106[45.0] \mathrm{Cr}$ \\
\hline ClF12 & $\mathrm{Cl}$ & 12 & Cr 114 [51.3] Iso & Iso $95[11.1] \mathrm{SmC}_{\mathrm{a}} \mathrm{P}_{\mathrm{A}}{ }^{\mathrm{A}} 75[37.1] \mathrm{Cr}$ \\
\hline MF12 & $\mathrm{CH}_{3}$ & 12 & Cr $90[40.4]$ Iso & Iso $88[13.9] \mathrm{SmC}_{\mathrm{a}} \mathrm{P}_{\mathrm{A}}{ }^{d} 72[31.9] \mathrm{Cr}$ \\
\hline
\end{tabular}

${ }^{a}$ Peak temperatures from DSC with rate $10 \mathrm{~K} \mathrm{~min}^{-1}$; for phase transitions in the second heating scan see Table S1; abbreviations: Cr $=$ crystalline solid; DC = dark conglomerate phase; $\mathrm{SmC}_{\mathrm{a}} \mathrm{P}_{\mathrm{A}}=$ anticlinic tilted antiferroelectric SmC phase; Iso = isotropic liquid. ${ }^{b}$ Obtained on cooling with $2 \mathrm{~K}$ $\mathrm{min}^{-1} .{ }^{c}$ Transition enthalpy value could not be determined for the DC-Cr transition due to overlapping. ${ }^{d}$ The spontaneous polarization value $\left(P_{\mathrm{s}}\right)$ calculated in the $\mathrm{SmC}_{\mathrm{a}} \mathrm{P}_{\mathrm{A}}$ phase for FF12 is $460 \mathrm{nC} \mathrm{cm}^{-2}$; for ClF12 is $480 \mathrm{nC} \mathrm{cm}{ }^{-2}$ and that for MF12 is $640 \mathrm{nC} \mathrm{cm}{ }^{-2}$ (representative current response curves are shown in Fig. S11).

\subsection{Methods}

The mesophase behaviour and transition temperatures were measured using a Mettler FP-82 HT hot stage and a control unit in conjunction with a Nikon Optiphot-2 polarizing microscope. The associated enthalpies were obtained from DSC-thermograms which were recorded on a Perkin-Elmer DSC-7 with heating and cooling rates of $10 \mathrm{~K} \mathrm{~min}^{-1}$. Electro-optical switching characteristics were examined in $6 \mu \mathrm{m}$ polyimide coated ITO cells (EHC Japan) using the triangular-wave method. XRD patterns were recorded with a 2D detector (Vantec-500, Bruker). Ni filtered and pin hole collimated $\mathrm{CuK}_{\alpha}$ radiation was used. The exposure time was $15 \mathrm{~min}$ and the sample to detector distance was 8.95 and $26.7 \mathrm{~cm}$ for wide angle and small angle scattering experiments, respectively. Samples were aligned by slow cooling (rate: $1 \mathrm{~K} \mathrm{~min}^{-1}$ to $0.1 \mathrm{~K} \mathrm{~min}^{-1}$ ) of a small droplet on a glass plate and takes place at the sample-air interface. The samples were held on a temperature-controlled heating stage.

\section{Results and discussion}

\subsection{Mesomorphic properties of compounds BrFn depending on terminal alkyl chain length}

The phase sequences, transition temperatures $\left({ }^{\circ} \mathrm{C}\right)$ and associated phase transition enthalpies $\left(\mathrm{kJ} \mathrm{mol}^{-1}\right)$ are summarized in Table 1 (see also Table $\mathrm{S} 1 \dagger$ for data from the second heating scans). In the series of the bromosubstituted compounds BrFn only the shortest homologue BrF4 having a relatively high melting point at $T=157{ }^{\circ} \mathrm{C}$ is non-mesomorphic. Also for the next homologue BrF6 a direct transition from the crystalline state to the isotropic liquid takes place on heating at $126^{\circ} \mathrm{C}$, but on cooling from the isotropic state a highly viscous optically isotropic mesophase appears at $T=96{ }^{\circ} \mathrm{C}$, as indicated by microscopy between crossed polarizers. Rotating the analyzer by a small angle out of the precise $90^{\circ}$ position leads to the appearance of dark and bright domains. Rotating the analyzer in the opposite direction reverses the dark and bright domains (see Fig. 1 for compound BrF12). Rotating the sample between crossed polarizers does not lead to any change and this indicates that the distinct regions represent chiral domains with opposite handedness, as typical for dark conglomerate phases (DC phases). No crystallization of this DC phase is observed upon cooling to room temperature. In the following heating cycles crystallization takes place either in the DC phase region or after transition of the DC phase to the isotropic liquid (see Fig. S1†). No crystallization is observed for any of the next homologues with $n=8-14$ (see Table 1 and Fig. 2b), even after storage for one year at room temperature.

All compounds BrF8-BrF14 have very similar transition temperatures. The melting of the DC phases (second heating scans) takes place around $106{ }^{\circ} \mathrm{C}$ and the formation of the DC phase on cooling occurs between 96 and $99{ }^{\circ} \mathrm{C}$ (see Table 1 and Fig. 2a). Hence, there is a supercooling of this phase transition by about $8 \mathrm{~K}$ (peak temperatures), which is found nearly 

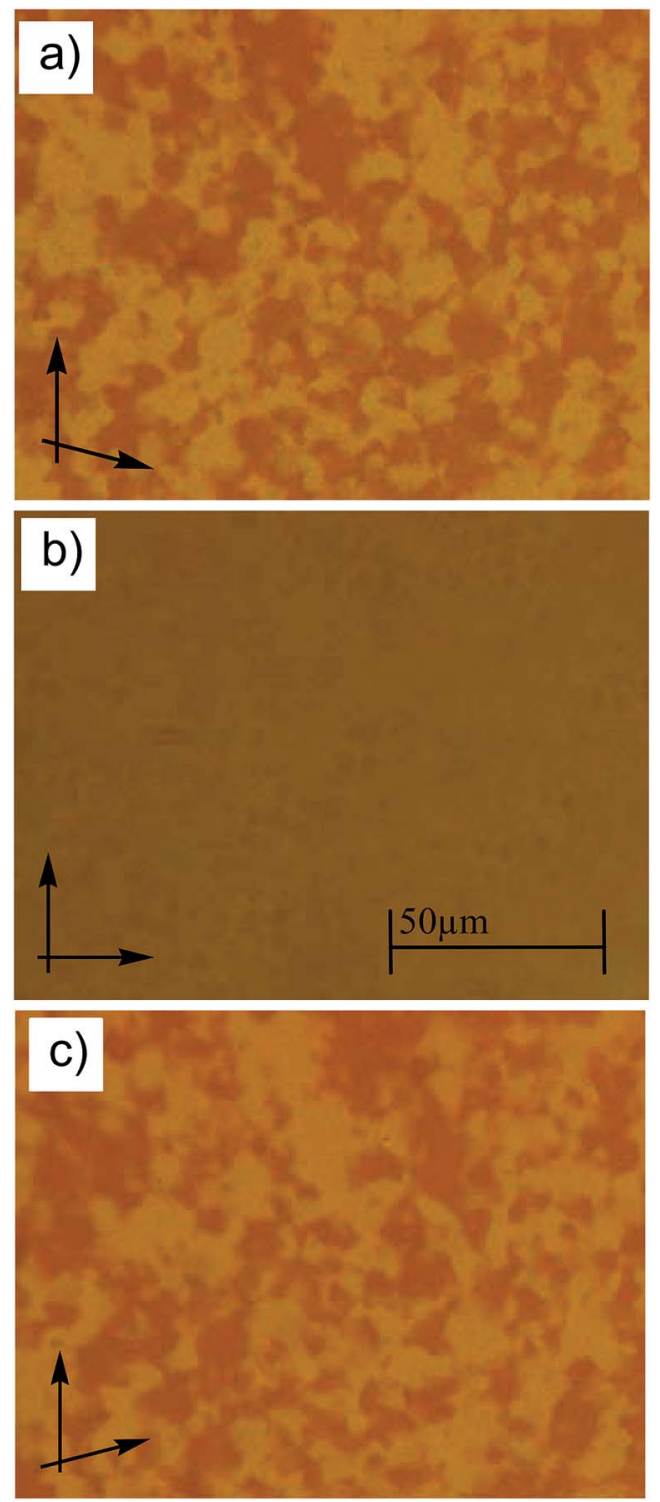

Fig. 1 Textures of the DC phase of compound BrF12 at $T=80^{\circ} \mathrm{C}$ : (b) between crossed polarizers and (a) after rotating one polarizer by $7^{\circ}$ from the crossed position in clock-wise direction and (c) in the anticlockwise direction, showing dark and bright domains, indicating the presence of areas with opposite chirality sense.

independent of the scanning rate $\left(2\right.$ or $\left.10 \mathrm{~K} \mathrm{~min}^{-1}\right)$. The formation of the DC phases is associated with relatively high transition enthalpies, ranging between $\Delta H \sim 23.8$ and $28.5 \mathrm{~kJ}$ $\mathrm{mol}^{-1}$, only slightly rising with growing chain length. Upon further chain elongation for BrF16 with $n=16$, the DC phase becomes instable and immediately after its formation crystallization takes place. For the longest homologue BrF18 $(n=18)$ the DC phase is completely removed and only a birefringent crystalline phase is observed.

In electro-optical experiments no current peak could be observed in the DC phases of any of the prepared materials BrF6-BrF14 and also no birefringence is induced under an applied triangular wave voltage up to $200 \mathrm{Vpp}$ in a $6 \mu \mathrm{m}$ ITO cell. This behaviour is similar to those known for soft crystalline

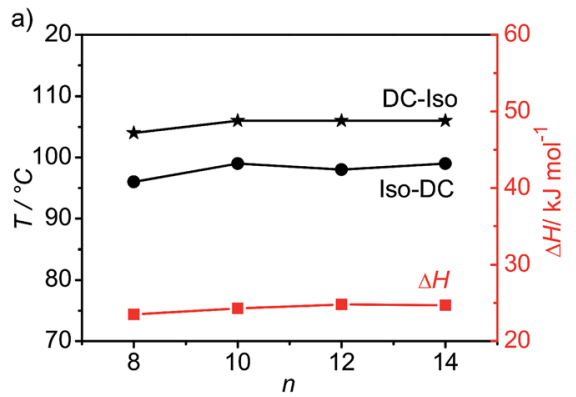

b)

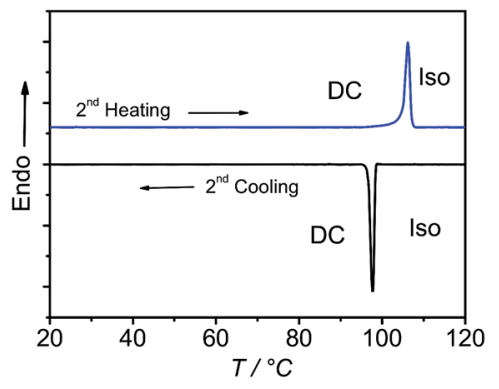

Fig. 2 (a) Dependence of DC-Iso transition temperatures (on heating and cooling scans with $10 \mathrm{~K} \mathrm{~min}^{-1}$ ) and transition enthalpy values (on cooling from the isotropic liquid) of compounds BrF8-BrF14 depending on alkyl chain length $n$ and (b) DSC heating and cooling curves of compound BrF12 with a rate of $10 \mathrm{~K} \mathrm{~min}^{-1}$.

HNF phases ( $B_{4}$ phases) and the DC phases of other related azobenzene based bent core mesogens, ${ }^{43,44}$ but it is clearly distinct from most of the fluid sponge-like smectic phases.

XRD investigation of the DC phases of compounds BrF6, BrF8, BrF12 and BrF14 (see Fig. 3 a and b, 4 and S2-5 $\dagger$ ) shows an intense reflection with $d$-values in between half of the molecular length $L_{\mathrm{mol}} / 2$ and the full length $L_{\mathrm{mol}}$ (see Fig. 3c). For the determination of $L_{\mathrm{mol}}$ a $120^{\circ} \mathrm{V}$-shaped conformation with alltrans alkyl chains was assumed (see Fig. S6 $\dagger$ ). The $d / L_{\text {mol }}$ ratio was thus calculated to be in the range of $0.78-0.80$ for all investigated compounds.

A linear increase of the $d$-values is observed with increasing length of the terminal chains from $d=3.46 \mathrm{~nm}$ for BrF6 to $d=$ $4.76 \mathrm{~nm}$ for BrF14 (Fig. 3c). Thus the intense small angle scattering is assigned to a layer reflection. The $d / L$ ratio around $0.78-0.80$ would, according to $d / L_{\mathrm{mol}}=\cos \beta$, allow a tilt angle of the molecules of around $38^{\circ}$. This relatively large difference between $d$ and $L_{\text {mol }}$ is similarly found for the DC phases of the related 4-iodo and 4-methylresorcinols IF $\boldsymbol{n}$ and $\mathbf{M n},{ }^{43,44}$ but distinguishes these DC phases from the previously reported HNF phases where $d$ is usually close to the molecular length. ${ }^{24,25}$ No alignment could be achieved and therefore in the 2D patterns all scatterings form closed rings with uniform intensity distribution (see Fig. 3a). This is due to the disordered mesoscale structure, which is an inherent and very typical feature of all DC phases and leads to their optically isotropic appearance as well as to a broadening of the scattering; the domain size (determined using the Scherrer equation and assuming $K=1)^{50}$ is in the range of $30-42 \mathrm{~nm}$ and grows with increasing alkyl chain length (see Fig. 3c). 


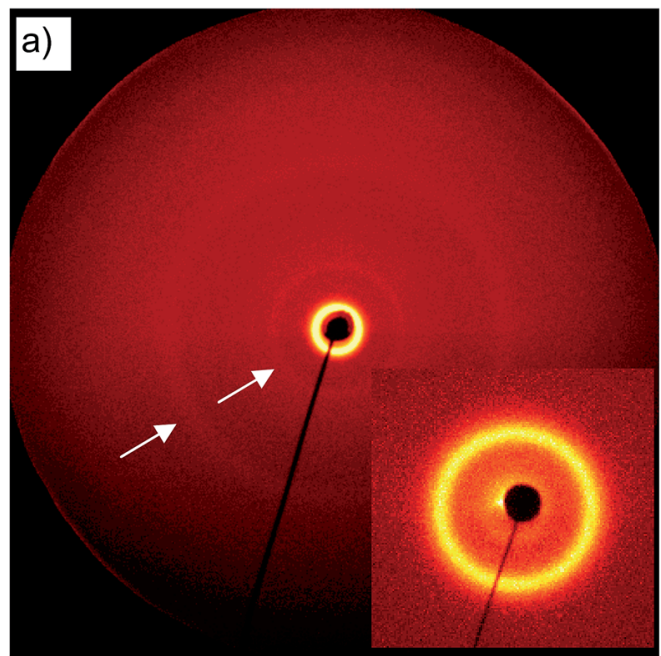

b)

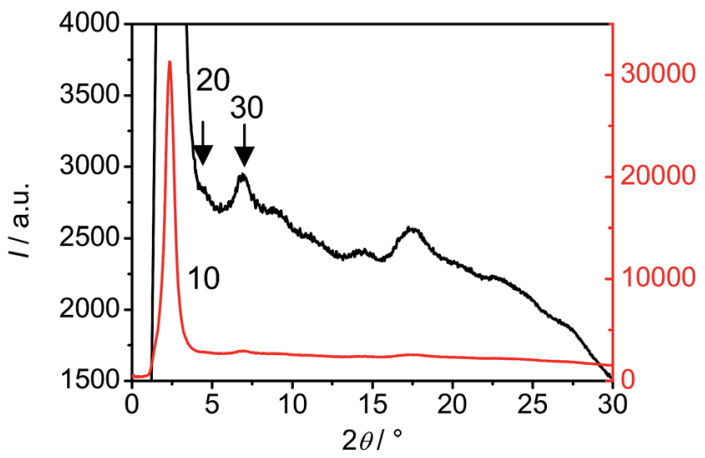

c)

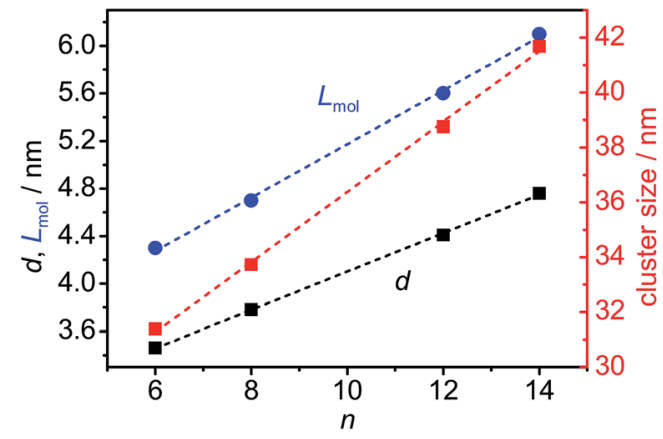

Fig. 3 (a) $2 \mathrm{D}$ XRD pattern of the $\mathrm{DC}$ phase of $\mathrm{BrF} 8$ at $T=90^{\circ} \mathrm{C}$, the inset shows the small angle region; (b) $2 \theta$-scans over this XRD pattern; (c) dependence of $d$-values, molecular lengths $\left(L_{\text {moli }}\right.$; the used conformation is shown in Fig. S6 $\dagger$ ) and cluster size (determined using the Scherrer equation and assuming $K=1$ ) in the DC phases of compounds BrF6-BrF14 on the chain length.

The $2 \theta$ scan over the diffraction pattern of compound BrF8 is shown in Fig. 3b, those of compounds BrF6, BrF12 and BrF14 are collated in Fig. 4. Beside the strong layer reflections very weak and broad scattering maxima are observed in the medium angle region $\left(2 \theta=5-9^{\circ}\right)$ and in the wide angle region $(2 \theta=14-$ $\left.28^{\circ}\right)$. This pattern excludes fluid sponge phases, which would show exclusively one completely diffuse wide angle scattering besides the layer reflection. The wide angle scattering is, similarly to the HNF phases, characterized by several scattering
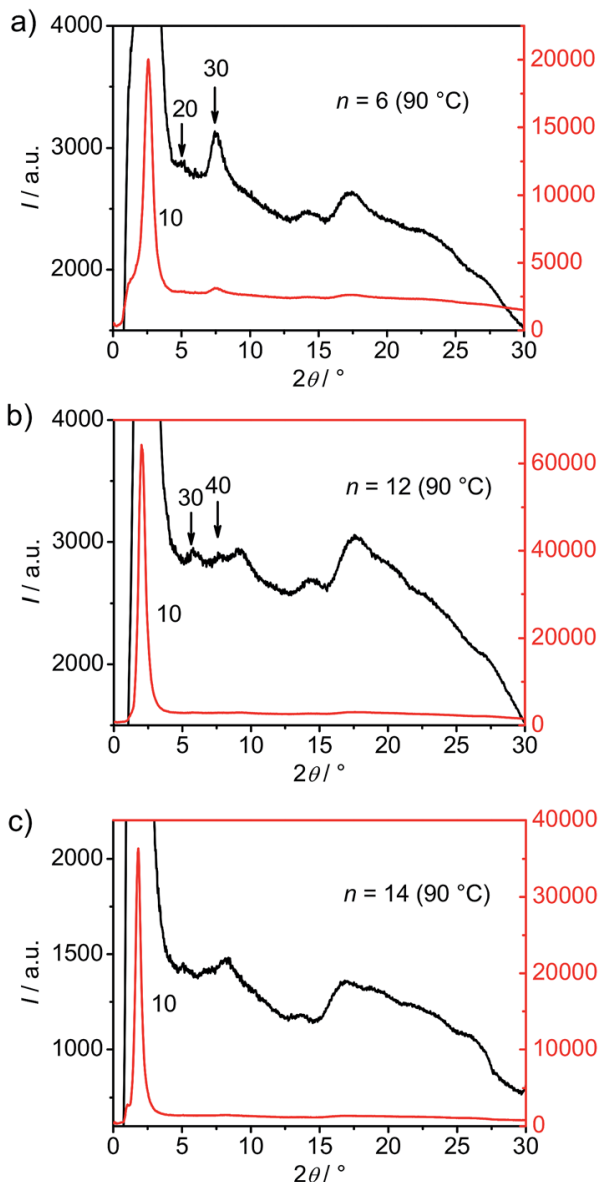

Fig. 4 Comparison of $2 \theta$-scan over the XRD patterns of the $D C$ phase of (a) BrF6, (b) BrF12 and (c) BrF14 at $T=90^{\circ} \mathrm{C}$ (for more details, see Fig. $\mathrm{S} 2-\mathrm{S} 5 \dagger$ )

maxima up to $2 \theta=28^{\circ}$. However, in contrast to typical patterns of HNF phases ( $\mathrm{B}_{4}$ phases, see Fig. $\left.5 \mathrm{~b}\right)$, the wide angle reflections are much broader and have significantly reduced intensity (compare red line in Fig. 5a with $5 \mathrm{~b}$, both shown in the logarithmic scale). For compounds BrF8-BrF12 most reflections in the medium angle region can be indexed as harmonics (up to $4^{\text {th }}$ order) of the layer reflection (see Fig. 4 and S2-S5†), as it is also the case for the previously reported $\mathbf{M} \boldsymbol{n}$ compounds $\mathbf{s}^{\mathbf{4}}$ and usually found for HNF phases. ${ }^{18,24-26}$ Only the XRD pattern of compound BrF14, the compound with the longest alkyl chain among the compounds with stable DC phases, appears a bit different from the others, as the medium angle scatterings cannot be assigned as higher order layer reflections and also the shape of the wide angle scattering is a bit different (Fig. 4c).

Fig. 5a shows a comparison of the $2 \theta$-scans of the DC phases of the related compound $\mathbf{M 1 4}\left(\mathrm{Y}=\mathrm{CH}_{3}\right), \operatorname{BrF14}(\mathrm{Y}=\mathrm{Br})$ and IF14 ( $\mathrm{Y}=\mathrm{I})$ all having the same chain length. It clearly indicates that, though the position of the 10 reflection is nearly identical in all cases, the positions and intensities of the medium and wide angle scattering maxima are very distinct for the halogen substituted compounds IF14 and BrF14 compared to the methyl substituted compound M14. The scattering intensity of the iodo compounds IFn is the lowest, followed by the bromine 


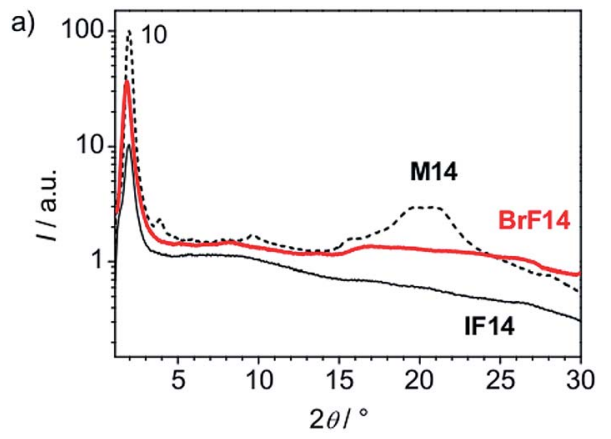

b)

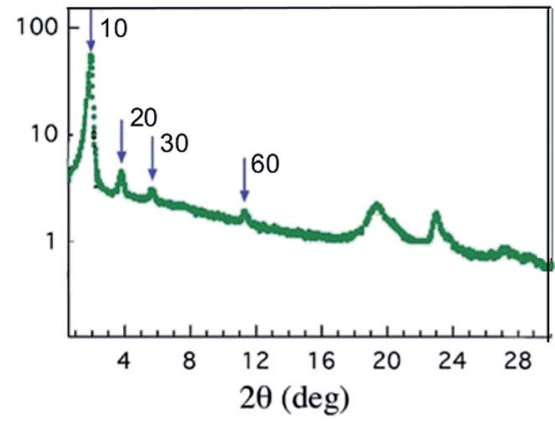

Fig. 5 (a) Comparison of the $2 \theta$-scans of the DC phases of compounds BrF14, IF14 and M14 (base line is shifted for better visibility; the scattering intensity of the IFn compounds is so low that scattering by air contributes to the diffuse scattering in the medium angle range $\left(5-10^{\circ}\right)$ of the XRD pattern of these I-substituted compounds) and (b) typical $2 \theta$-scans of a HNF phase ( $\mathrm{B}_{4}$ phase) of a benzylideneaniline based bent-core mesogen ( $\mathrm{P}$-8-OPIMB) reproduced with modifications and permission from ref. 21, copyright RSC 2009

substituted compounds BrFn and compounds Mn. Though having a higher intensity the wide angle scattering profile of the bromo compound BrF14 is similar to IF14, indicating similarities in the molecular organizations in their DC phases.

\subsection{Investigation of mixtures of compounds BrFn with 5-CB}

It is known that HNF phases of benzylideneanilines can be diluted by nematic LC hosts to a high degree (>95\%) without loss of the chirality. ${ }^{51}$ This is a direct consequence of the helical nano-filament structure of these phases, allowing a swelling of the filaments by the nematic LC and transfer of chirality from the nano-filaments to the nematic LC. This effect is not observed for the sponge type liquid crystalline DC phases involving distorted fluid smectic layers. Therefore, investigation of mixtures with $4^{\prime}$-n-pentyl-4-cyanobiphenyl (5-CB) could be used as a tool providing additional information about the microstructure of the DC phases of compounds BrFn.

The 1 : 1 mixtures of BrF8 or BrF10 with 5CB do not show any DC phase. On heating these mixtures only a direct transition from the crystalline material to the isotropic liquid state occurs at $57{ }^{\circ} \mathrm{C}$ and $54{ }^{\circ} \mathrm{C}$, respectively (Table 2). On cooling both of these mixtures form a nematic phase which crystallizes with formation of highly birefringent crystalline phases at $T \sim 36{ }^{\circ} \mathrm{C}$ and $33{ }^{\circ} \mathrm{C}$, respectively (see Table 2), but no DC phase is formed. The next homologue BrF12 behaves differently; on heating this
Table 2 Phase transition temperatures and mesophase types of $1: 1$ mixtures of $5-\mathrm{CB}$ and compounds $\mathrm{BrF} 8-\mathrm{BrF} 18$ and comparison with related 4-methylresorcinol derivatives $\mathrm{M} 14-\mathrm{M} 18^{a}$ (ref. 44)

\begin{tabular}{|c|c|c|}
\hline Mixture & Heating $T^{\circ} \mathrm{C}$ & Cooling $T^{\circ} \mathrm{C}$ \\
\hline $\mathrm{BrF8}+5-\mathrm{CB}$ & Cr 57 Iso & Iso $43 \mathrm{~N} 36 \mathrm{Cr}$ \\
\hline BrF10 + 5-CB & Cr 54 Iso & Iso $42 \mathrm{~N} 33 \mathrm{Cr}$ \\
\hline BrF12 + 5-CB & $\mathrm{Cr}^{[*]} 40$ DC 55 Iso & Iso $53 \mathrm{DC} 38 \mathrm{Cr}^{[*]}$ \\
\hline BrF14 + 5-CB & Cr 38 DC 64 Iso & Iso $46 \mathrm{DC} 35 \mathrm{Cr}$ \\
\hline BrF16 + 5-CB & $\mathrm{Cr}_{1} 33 \mathrm{Cr}_{2} 69$ Iso & Iso $63 \mathrm{Cr}$ \\
\hline BrF18 + 5-CB & $\mathrm{Cr}_{1} 42 \mathrm{Cr}_{2} 75$ Iso & Iso $65 \mathrm{Cr}$ \\
\hline M14 + 5-CB & Cr 85 Iso & Iso $54 \mathrm{~N} 53 \mathrm{Cr}$ \\
\hline $\mathrm{M16}+5-\mathrm{CB}$ & Cr 64 DC 73 Iso & Iso $66 \mathrm{DC}$ \\
\hline $\mathrm{M} 18+5-\mathrm{CB}$ & DC 77 Iso & Iso $77 \mathrm{DC}$ \\
\hline
\end{tabular}

${ }^{a}$ Transition temperatures were taken from the observed textures using the polarized optical microscopy; abbreviations: $\mathrm{N}=$ nematic phase; $\mathrm{Cr}^{\left[{ }^{*}\right]}=$ crystalline phase composed of a conglomerate of chiral domains; for other abbreviations please see Table 1.

mixture a transition from the crystalline phase to the DC phase occurs at $40{ }^{\circ} \mathrm{C}$ (see Fig. S7d-f $\dagger$ ). On further heating a transition from the DC phase to the isotropic liquid takes place at $55^{\circ} \mathrm{C}$. On cooling this mixture from the isotropic liquid the transition to the DC phase takes place at $T \sim 53{ }^{\circ} \mathrm{C}$ followed by crystallization at $38{ }^{\circ} \mathrm{C}$. Interestingly, this crystalline phase is nearly isotropic and composed of domains with opposite handedness (see Fig. S7a-c $\dagger$ ). The mixture of the next homologue BrF14 shows similar behaviour to that of BrF12, except that this weakly birefringent crystalline phase is achiral or the chiral domains are too small to be detected. Mixing the longer crystalline compounds BrF16 and BrF18 with 5-CB does not give any DC phases (see Table 2).

The significant destabilization of the DC phases by 5-CB confirms that the DC phases of compounds BrFn should be different from the classical HNF phases. ${ }^{21,24-26}$ It appears that these phases are formed by smaller nano-domains instead of long helical nano-filaments, in line with the results of the XRD studies showing relatively broad wide angle scatterings. Because no extended filaments are formed, no gel-like networks of these fibers are possible and therefore these compounds can take up only a limited amount of 5-CB, which is directly incorporated between the bent-core molecules and thus reduces the stability of the DC phases. The highest tendency for DC phase formation appears to be provided by the medium chain compounds BrF12 and BrF14. Comparison with results obtained with related compounds indicate that the 5-CB mixtures of compounds BrFn behave very similar to the 5-CB mixtures of the iodo compounds IFn, ${ }^{\mathbf{4 3}}$ whereas for the 4methylresorcinols Mn the DC phases in the mixtures have higher stability and their regions are shifted to longer alkyl chain lengths (Table 2), indicating slightly more stable aggregates.

\subsection{Comparison of different types of 4-substituted resorcinol based BCLCs with azobenzene units}

In Table 3 compound BrF12 is compared with the nonsubstituted compound $\mathbf{H 1 2}$ (ref. 52) and related BCLCs with 
Table 3 Phase transition temperatures $\left(T /{ }^{\circ} \mathrm{C}\right)$ and mesophase types as observed for different types of 4-substituted resorcinols $(Y)$ with azobenzene wings and the effect of peripheral F-atoms $(\mathrm{X}=\mathrm{H}, \mathrm{F})^{a}$

\begin{tabular}{|c|c|c|c|c|c|c|}
\hline H12 & $\mathrm{H}$ & 7 & & $\mathrm{H}$ & Cr 145 Iso & 52 \\
\hline HF12 & $\mathrm{H}$ & & & $F$ & Cr 138 Iso & \\
\hline F12 & $\mathrm{F}$ & 13 & 1.60 & $\mathrm{H}$ & Cr 120 Iso & 47 \\
\hline FF12 & $\mathrm{F}$ & & & $F$ & Cr $120\left(\mathrm{SmCP}_{\mathrm{A}} 119\right)$ Iso & \\
\hline Cl12 & $\mathrm{Cl}$ & 27 & 1.69 & $\mathrm{H}$ & $\mathrm{Cr}_{1} 90 \mathrm{Cr}_{2} 103$ (N 97) Iso & 47 \\
\hline IF12 & I & & & $F$ & DC 111 Iso & 43 \\
\hline M12 & $\mathrm{CH}_{3}$ & 32 & 0.37 & $\mathrm{H}$ & DC 102 Iso & 44 \\
\hline MF12 & $\mathrm{CH}_{3}$ & & & $F$ & $\mathrm{Cr} 90 \mathrm{SmCP}_{\mathrm{A}} 92$ Iso & \\
\hline CN12 & $\mathrm{CN}$ & 23 & 4.18 & $\mathrm{H}$ & Cr $71\left(\mathrm{SmC}_{\mathrm{s}} \mathrm{P}_{\mathrm{A}} 70\right) \mathrm{M}_{1} 75 \mathrm{SmC}_{\mathrm{s}} \mathrm{P}_{\mathrm{F}} 83 \mathrm{SmC}_{\mathrm{s}} \mathrm{P}_{\mathrm{R}}^{\left[{ }^{[*]}\right.} 96 \mathrm{SmC} 127 \mathrm{~N} 137$ Iso & 32 \\
\hline CNF12 & $\mathrm{CN}$ & & & $F$ & Cr $104 \mathrm{SmC}_{\mathrm{S}} \mathrm{P}_{\mathrm{A}} 108 \mathrm{SmC}_{\mathrm{s}} \mathrm{P}_{\mathrm{R}}{ }^{[*]} 135 \mathrm{SmA} 147$ Iso & $d$ \\
\hline
\end{tabular}

${ }^{a}$ Abbreviations: $\mathrm{N}=$ nematic phase; $\mathrm{SmA}=$ nonpolar smectic A phase; $\mathrm{SmC}=$ paraelectric smectic C phase; $\mathrm{SmC}_{\mathrm{S}} \mathrm{P}_{\mathrm{R}}{ }^{\left[{ }^{*}\right]}=\operatorname{synclinic}$ tilted SmC phase composed of $\mathrm{SmC}_{\mathrm{S}} \mathrm{P}_{\mathrm{F}}$ domains with randomized polar directions, homeotropically aligned samples of this phase are composed of a conglomerate of chiral domains; $\mathrm{SmC}_{\mathrm{S}} \mathrm{P}_{\mathrm{F}}=$ polar SmC phase composed of enlarged ferroelectric domains; $\mathrm{M}_{1}=$ highly viscous antiferroelectric switching SmC phase; $\mathrm{SmCP}_{\mathrm{A}}=$ antiferroelectric switching $\mathrm{SmC}$ phase (B2 phase); $\mathrm{SmC}_{\mathrm{S}} \mathrm{P}_{\mathrm{A}}=$ synclinic tilted antiferroelectric SmC phase (B2 phase); for other abbreviations see Table $1 .{ }^{b}$ Crystal volumes of Immirzi. ${ }^{53}$ Dipole moments of the corresponding phenyl derivatives. ${ }^{54} d$ Unpublished data.

other substituents in the 4-position of the resorcinol core, like halogens $(\mathrm{Y}=\mathrm{F}, \mathrm{Cl}, \mathrm{I})$, methyl and cyano. Comparison of the different azobenzene based BCLCs (all with $n=12$ ) indicates that there is a tendency for reduction of the melting points by the substituents $\mathrm{Y}$ which becomes the more important the larger these substituents are. Thus LC phases can be observed for most of the 4-substituted compounds, whereas the nonsubstituted compounds $\mathbf{H 1 2}$ and HF12 represent relatively high melting solids. There appears to be a dependence of the phase type on the volume of $\mathrm{Y}$ (crystal volumes cv of Immirzi ${ }^{53}$ ) and the polarity of the $\mathrm{C}-\mathrm{Y}$ bond (dipole moments $\mu$ of the $\mathrm{Ph}-\mathrm{Y}$ compound $s^{54}$ ). For molecules with $\mathrm{X}=\mathrm{H}$ and having polar substituents $\mathrm{Y}$ at the resorcinol core no LC phase is observed $(\mathrm{Y}$ $=\mathrm{F}, \mathrm{I})$ or nematic phases are dominating $(\mathrm{Y}=\mathrm{Cl}, \mathrm{Br}, \mathrm{CN})$, whereas the nonpolar methyl group is obviously favourable for the formation of DC phases (compound M12). Introducing peripheral F-substituents increases the tendency for formation of polar SmC phases $\left(\mathrm{SmCP}_{\mathrm{A}}\right)$ if the 4-substituent is small $(\mathrm{Y}=$ $\mathrm{F}, \mathrm{Cl}, \mathrm{CN}$ ). Formation of DC phases is only supported by peripheral fluorination of BCLCs with large and polar substituents $\mathrm{Y}(\mathrm{Y}=\mathrm{Br}, \mathrm{I})$.

So, overall, large substituents in the 4-position at the resorcinol core appear to be favourable for DC phase formation, although there is an additional effect of peripheral F-substitution. Obviously the effect of peripheral fluorine substitution is the reverse for BCLCs with polar and non-polar substituents
Y. While for the methyl-substituted compounds the introduction of $\mathrm{F}$ removes the $\mathrm{DC}$ phase and a $\mathrm{SmCP}_{\mathrm{A}}$ phase is formed, for compounds with large polar halogens $(\mathrm{Br}, \mathrm{I})$ introduction of peripheral F-substitution induces DC phases. The reason for this behaviour is not yet clear.

As can be deduced from the comparison in Fig. 2a and 6a, the transition enthalpy values of the DC-Iso transitions and the corresponding transition enthalpy values of the iodine substituted compounds IF8-IF14 and for the bromine substituted analogues BrF8-BrF14 are in the same range, once again confirming the similarity between the DC phases of the two series, already concluded from the similarity of the XRD patterns. Nevertheless, the DC-Iso transition temperatures and the related transition enthalpy values of compounds IF $\boldsymbol{n}$ are slightly higher (by $\sim 3$ to $10 \mathrm{~K}$ and $\sim 2$ to $6 \mathrm{~kJ} \mathrm{~mol}^{-1}$, respectively) than those of their bromine substituted analogues BrFn. This might be due to the increased polarizability provided by iodine, increasing the attractive dispersion forces between the molecules. In line with increased intermolecular interactions a denser packing of compounds IF $\boldsymbol{n}$ could provide a stronger effect of molecular conformational chirality (helicity) on the aggregate stability and aggregate size. Also the observation that compounds IF8-IF14 exhibit exclusively the DC phases and do not show any crystallization, while compounds BrF8-BrF14 show crystalline phases in the first heating and thus form monotropic DC phases (though, the DC phases once formed 
a)

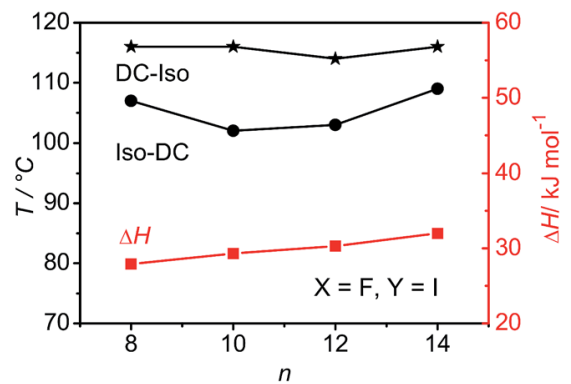

b)

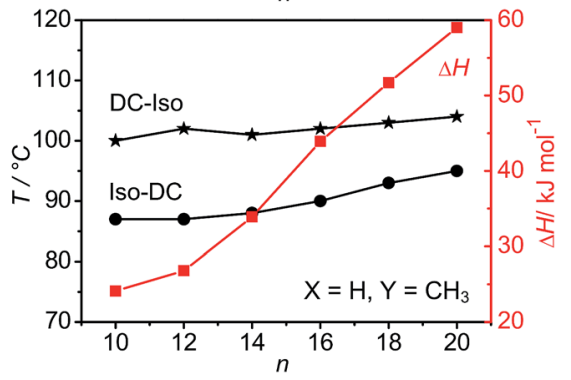

Fig. 6 Dependence of DC-Iso transition temperatures (on heating and cooling scans with $10 \mathrm{~K} \mathrm{~min}^{-1}$ ) and transition enthalpy values (on cooling from the isotropic liquid) of two series of compounds related to BrFn (a) the 4-iodine-substituted compounds IF8-IF14 (ref. 43) and (b) the 4-methyl-substituted compounds M10-M20 (ref. 44) depending on the alkyl chain length $n$.

also do not crystallize) is in line with a stronger distortion of the long range molecular packing in the case of the iodo compounds. This could be attributed to the larger size of iodine compared to $\mathrm{Br}$, which could provide a stronger helical twist of the molecular conformations.

Comparison of the series BrFn (Fig. 2a) with the methylsubstituted compounds $\mathbf{M n}$ (Fig. 6b) with chain length $n=10$ 14 indicates about $10 \mathrm{~K}$ higher DC-Iso transition temperatures for the compound having the more polar bromine substituent (and an additional peripheral F-substituent). The DC-Iso transition enthalpy values are comparable in both series, but for compound $\mathbf{M} \boldsymbol{n}$ there is a much stronger enthalpy increase upon chain elongation and in this case alkyl chain crystallization significantly contributes to the transition enthalpies. ${ }^{44}$ There are clear difference also in the XRD patterns of the methyl substituted and the halogen substituted BCLCs (see Fig. 5a), indicating that the DC phases of compounds $\mathbf{M n}$ are different from those of BrFn and IFn. The presence of only lower harmonics (up to the $4^{\text {th }}$ ) of the layer reflections $\left(5^{\text {th }}\right.$ and $6^{\text {th }}$ order harmonics of the layer reflections has been reported for typical $\mathrm{B}_{4}$ phases, see for example Fig. 5b (ref. 21) and the significantly increased broadness of the wide angle scatterings indicates a stronger distortion of layer structures and filament formation in the case of the halogen substituted compounds. This is also in line with the reduced resistance of the DC phases of compounds BrFn and IFn against dilution with the nematic phase of 5-CB (see Table 2).

DFT calculations of the model compounds F1, Br1, I1, M1 and CN1 with $n=1$ were performed with the Gaussian 09 package, ${ }^{55}$ using the B3LYP functional and LANL2DZ basis set using the solvation model IEFPCM in solvent chlorobenzene to investigate the effects of the 4-substituents on the bending angle $(\gamma)$ and on the twist of the wing groups in the lowest energy conformation. The results are summarized in Fig. 7 where two different projections are shown and in Table 4, providing numerical values of bending angles $\gamma$ and twist angles $\alpha$ and $\beta$. In Fig. 7a the view is perpendicular to the resorcinol ring and in Fig. $7 \mathrm{~b}$ the view is parallel to this ring along the wing in the 3-position. For all compounds, except CN1, the bending angle $\gamma$ is not significantly affected by the 4substituent and is around $120-123^{\circ}$ in all cases (see Fig. 7a and Table 4). Only for CN1 it is increased to about $130^{\circ}$ due to the dipole interactions between the $\mathrm{CN}$ group and the adjacent $\mathrm{C}=\mathrm{O}$ group, in line with previous investigations. ${ }^{56}$ This contributes to the very different behaviour of the cyanoresorcinols CNn (ref. 31 and 32) compared to the other considered compounds (see Table 3 ).

The azobenzene units themselves are linear and the benzene rings in these wings as well as the $\mathrm{C}=\mathrm{O}$ groups of the carboxylate groups are nearly coplanar in all cases. Different minimum energy conformations result from the twist of the planes of the azobenzene wings with respect to the resorcinol core and thus to each other, leading to chiral conformers for all investigated compounds. The angle $\alpha_{1}$, which describes the twist between the plane of the azobenzene wing in the 1-position with respect to the plane of the resorcinol core, is around $50^{\circ}$ for all halogen substituted compounds. Larger differences can be found for the twist $\alpha_{2}$ of the azobenzenes in the 3-position which changes between $\alpha_{2}=49$ and $109^{\circ}$ (see Fig. 7b and Table 4). Overall, the effective twist between the planes of the two azobenzene wings $\beta$ increases in the order $\mathrm{F}<\mathrm{Br}<\mathrm{CH}_{3}<$ I roughly in line with the growing size of the 4-substituent (see cv in Table 3; only the effect of the $\mathrm{CH}_{3}$ group is larger than that of $\mathrm{Br}$ though their volumes are nearly equal). This is in line with the observed tendency of these molecules to form DC phases. Accordingly, no DC phase was found for any of the resorcinol and 4-fluororesorcinol derivatives, whereas DC phases were found for compounds with $\mathrm{Y}=\mathrm{Br}, \mathrm{CH}_{3}$ and I. Although for $\mathrm{Y}=\mathrm{CN}$ the twist angle $\beta$ is the largest, these molecules behave differently, due to the increased bending angle $\left(\gamma \sim 130^{\circ}\right)$ and the possibility of antiparallel compensation of the very large dipoles of these groups. Therefore, these CN-substituted compounds do not form DC phases, but preferably form nematic and SmC phases. Nevertheless, the large twist in the low energy conformation might be responsible for the formation of chiral domains in some of the birefringent SmC phases of these compounds $\left(\mathrm{SmC}_{\mathrm{S}} \mathrm{P}_{\mathrm{R}}{ }^{[*]}\right) \cdot{ }^{31,32}$

Based on the combination of experimentally observed structure property relationships (Table 3) and results of DFT calculations the following relationships between the molecular structure and formation of DC phases can be hypothesized. As the azobenzene wings are completely flat the only source of conformational chirality is in this case the central part of the molecules, i.e. the connections between the resorcinol core and azobenzene wings. For this reason the substitution in position 4 at the resorcinol is important and has a significant effect on the molecular conformation and hence the ability to form DC phases. Due to the rigidity of the azobenzenes the 


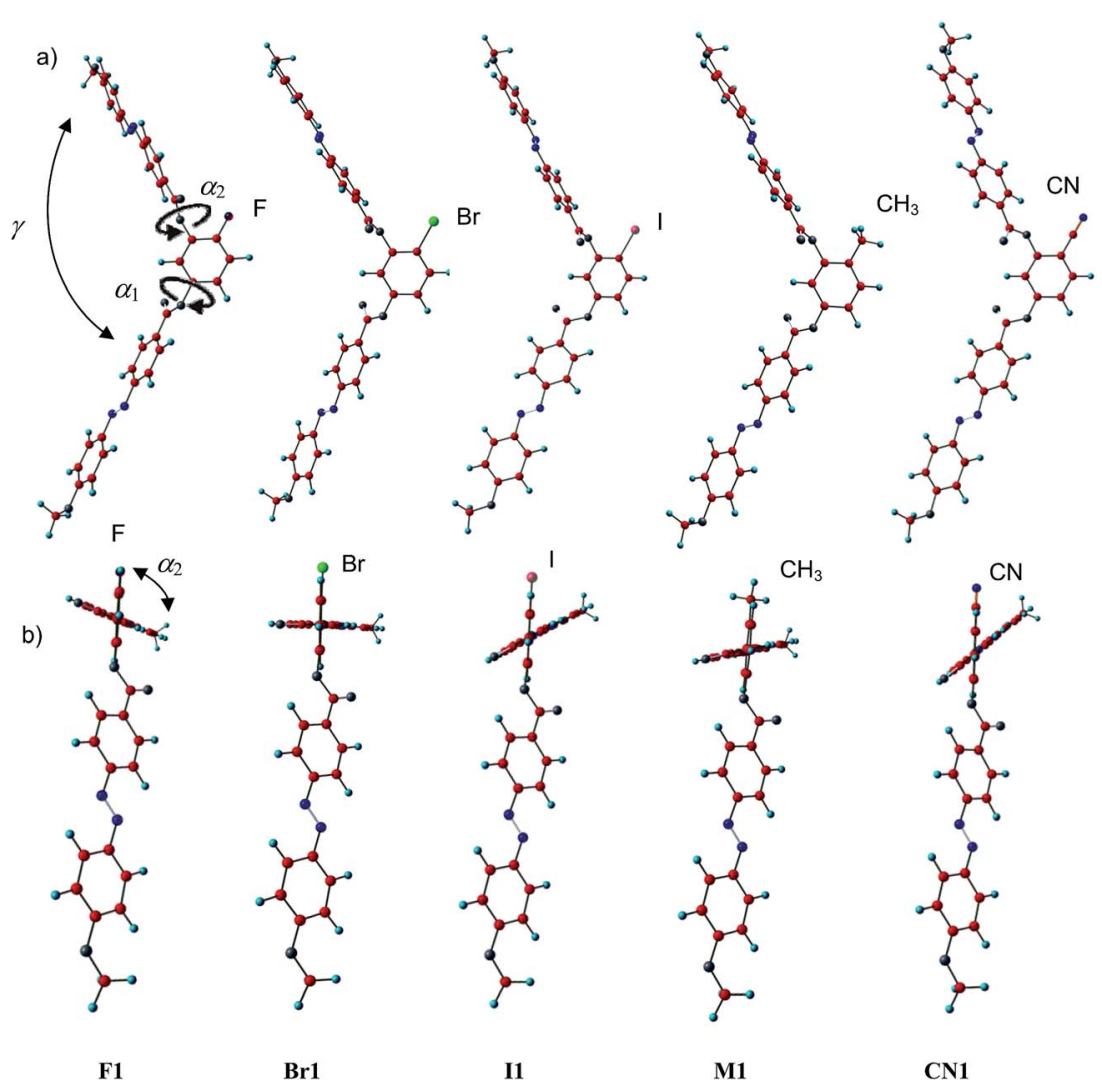

Fig. 7 Energy minimized molecular conformers of the model compounds $(n=1)$ as observed under two distinct perspectives, (a) perpendicular to the plane of the resorcinol core indicating changes of the bending angle $\gamma$ and $(b)$ along the azobenzene wing in the 3-position and parallel to the plane of the resorcinol core, indicating the distinct degrees of twist between the two planes of the azobenzene wings; the angles $\alpha_{1}, \alpha_{2}$ and $\gamma$ are explained for F1.

Table 4 Selected parameters of the energy minimized conformers obtained by DFT calculations of the distinct model compounds Y1 $(n=1)$ depending on the 4-substituent $\mathrm{Y}$ at the resorcinol core ${ }^{a}$

\begin{tabular}{llrll}
\hline $\mathrm{Y}$ & $\alpha_{1} /{ }^{\circ}$ & \multicolumn{1}{c}{$\alpha_{2} /^{\circ}$} & $\beta /{ }^{\circ}$ & $\gamma /{ }^{\circ}$ \\
\hline $\mathrm{F}$ & 50.9 & 109.1 & 31.8 & 121.5 \\
$\mathrm{Br}$ & 48.8 & 89.8 & 41.4 & 120.1 \\
$\mathrm{I}$ & 49.8 & 58.1 & 72.1 & 123.4 \\
$\mathrm{CH}_{3}$ & 53.6 & 72.4 & 54.0 & 119.9 \\
$\mathrm{CN}$ & 44.8 & 49.0 & 86.2 & 129.7
\end{tabular}

${ }^{a} \beta=$ twist between the planes of the azobenzenes, calculated according to $\beta=\left(90-\alpha_{1}\right)+\left(90-\alpha_{2}\right)$, where $\alpha_{1}$ and $\alpha_{2}$ represent the twist angles of the planes of the azobenzenes with respect to the plane of the resorcinol unit, ( $\alpha_{1}$ azobenzene in the 1-position, $\alpha_{2}$ in the 3 position); $\gamma=$ bending angle which is calculated as the angle between the lines connecting the terminal ether oxygens at the azobenzenes with the carbon atoms 1 and 3 of the resorcinol core, respectively.

conformational chirality provided by the core has a strong effect on the overall molecular shape, providing a strong distortion to any packing in layers/filaments, thus leading to strongly distorted types of semicrystalline DC phases. ${ }^{57}$ In contrast, other typical wing groups such as phenylbenzoates, ${ }^{2}$ benzylideneanilines $^{58}$ and biphenyls ${ }^{2}$ can themselves easily adapt twist conformations and can therefore contribute to the overall conformational chirality. In line with this, for such compounds a bulky substituent in the central core unit is not required for DC phase formation. Moreover, as the helical twist can arise in the peripheral wing units the molecular shape is less distorted and such compounds can more easily adapt to the organization in twisted layers and extended helical filaments, predominately leading to the previously reported types of DC phases, the LC smectic sponges (phenyl benzoates) and the soft crystalline HNF phases (benzylidene anilines), respectively.

\section{Conclusions and summary}

Bent-core molecules derived from 4-bromoresorcinol with peripherally fluorinated azobenzene wings $(\mathbf{B r F n})$ represent new materials forming optically isotropic DC phases composed of conglomerates of uniformly chiral domains, which can be observed for a chain length range $n=8-14$ as the only mesophase, whereas shorter and longer homologues form only birefringent crystalline phases. The DC phases of compounds with $n=10-14$ are stable down to ambient temperature and do not crystallize even after prolonged storage. For related compounds without the peripheral fluoro substitution (Brn $)$ a DC phase was observed for only one homologue $(n=10)$ as a monotropic phase, whereas the other homologues form monotropic nematic and $\mathrm{B}_{6}$ phases. $^{47}$ This indicates a strong DC phase stabilizing effect of peripheral F substitution in this case, which is reverse to the 
4-methylresorcinols, for which DC phases were found for the nonfluorinated compounds $\mathbf{M} \boldsymbol{n}$ whereas the fluorinated compounds MFn form antiferroelectric switching $\mathrm{SmCP}_{\mathrm{A}}$ phases (B2 phases). ${ }^{\mathbf{4}}$ $\mathrm{XRD}$ investigations and the relatively high viscosity of these DC phases indicate that they do not belong to the fluid sponge type smectic LC phases, but are more related to the soft crystalline HNF phases. However, in contrast to the classical HNF phases the helical nano-filaments appear to be not well developed, so that the helical twist gives rise to a strongly disordered structure formed by nanoscale twisted domains of crystallized aromatic cores separated by disordered alkyl chains. In this way the DC phases are similar to those formed by the related 4-iodoresorcinol derivatives, ${ }^{43}$ but distinct from those formed by the previously reported $\mathrm{B}_{4}$ type HNF phases of the benzylideneanilines. ${ }^{24}$ It is thought that for the compounds BrFn the filaments are disrupted into smaller segments, as also proposed for the methyl substituted compounds $\mathbf{M n}$, and it appears that the degree of disruption increases in the order Mn $<$ BrFn $<$ IFn.

DFT calculations allowed the estimation of the effects of the substituents $\mathrm{Y}$ on the minimum energy conformers. This indicates that the azobenzenes themselves are flat and that mainly steric effects of the substituent $Y$ lead to an increase of the twist between the planes of the azobenzene wings with increasing size of $\mathrm{Y}$. This appears to be favourable for chiral segregation and layer distortion, due to the difficulty in the parallel packing of these highly twisted molecular species. The strong layer distortion is thought to be responsible for the preferred formation of twisted nano-domains instead of sponge-like deformed layers or extended helical nano-filaments.

The effect of polarity on the molecular conformation is the strongest for the $\mathrm{CN}$ substituted compounds, giving rise to a less bent (more rod-like) molecular shape, which appears to be unfavourable for formation of DC phases, but favours the formation of nematic and SmC phases. Nevertheless, the strong twist between the planes of the azobenzenes leads to a high "strength of chirality" of the energy minimum conformers which allows chiral segregation even in some of their polarization randomized SmC phases $\left(\mathrm{SmC}_{\mathrm{S}} \mathrm{P}_{\mathrm{R}}{ }^{[*]}\right.$ phases).

In summary, the development of new types of DC phases depending on the molecular structure was investigated in a systematic way. Relationships between the molecular structure and formation of distinct types of DC phases were found and possible reasons for these relationships were hypothesized. We believe that this study will contribute to the improvement of the general knowledge about DC phases and the mechanisms of achiral symmetry breaking in soft matter as well as to the design of new molecules showing DC phases. BCLCs involving azo linkages are also very versatile materials due to their photochromic effects and high birefringence. Moreover, the trans-cis photoisomerization of the azobenzene wings in these BCLCs could lead to interesting perspectives for chirality switching and phase modulation by interaction with nonpolarized, linear or circular polarized light, i.e. to unique and potentially useful multifunctional chiral materials for application in high-density data storage systems, sensors, photonic switches and molecular logic gates. ${ }^{59,60}$ as well as with potential for discrimination of chiral physical forces and molecular species.

\section{Acknowledgements}

M. Alaasar is grateful to the Alexander von Humboldt Foundation for the research fellowship at the Martin-Luther University Halle-Wittenberg, Germany.

\section{References}

1 (a) R. A. Reddy and C. Tschierske, J. Mater. Chem., 2006, 16, 907; (b) H. Takezoe and Y. Takanishi, Jpn. J. Appl. Phys., 2006, 45, 597; (c) A. Eremin and A. Jakli, Soft Matter, 2013, 9, 615.

2 H. Takezoe, Top. Curr. Chem., 2012, 318, 303.

3 (a) F. Vera, J. L. Serrano and T. Sierra, Chem. Soc. Rev., 2009, 38, 781; (b) M. Lehmann, M. Jahr, B. Donnio, R. Graf, S. Gemming and I. Popov, Chem.-Eur. J., 2008, 14, 4414; (c) C. Roche, H.-J. Sun, M. E. Prendergast, P. Leowanawat, B. E. Patridge, P. A. Heiney, F. Araoka, R. Graf, H. W. Spiess, X. Zeng, G. Ungar and V. Percec, J. Am. Chem. Soc., 2014, 136, 7169-7185; (d) M. H. C. J. V. Houtem, F. Benaskar, C. F. C. Fitié, R. Martín-Rapún, J. A. J. M. Vekemans and E. W. Meijer, Org. Biomol. Chem., 2012, 10, 5898; (e) R. Q. Albuquerque, A. Timme, R. Kress, J. Senker and H.-W. Schmidt, Chem.-Eur. J., 2013, 19, 1647.

4 H. Nagayama, S. K. Varshney, M. Goto, F. Araoka, K. Ishikawa, V. Prasad and H. Takezoe, Angew. Chem., 2010, 49, 445.

5 (a) D. Pijper and B. L. Feringa, Soft Matter, 2008, 4, 1349; (b) K. Maeda and E. Yashima, Top. Curr. Chem., 2006, 265, 88; (c) C. C. Lee, C. Grenier, E. W. Meijer and A. P. H. J. Schenning, Chem. Soc. Rev., 2009, 38, 671; (d) W. Jin, Y. Yamamoto, T. Fukushima, N. Ishii, J. Kim, K. Kato, M. Takata and T. Aida, J. Am. Chem. Soc., 2008, 130, 9434.

6 J. V. Selinger, M. S. Spector and J. M. Schnur, J. Phys. Chem. B, 2001, 105, 1757.

7 E. Barry, Z. Hensel, Z. Dogic, M. Shribak and R. Oldenbourg, Phys. Rev. Lett., 2006, 96, 018305.

8 A. Lohr and F. Würthner, Angew. Chem., Int. Ed., 2008, 47, 1232.

9 (a) E. Yashima, K. Maeda, H. Iida, Y. Furusho and K. Nagai, Chem. Rev., 2009, 109, 6102; (b) H. Jinnai, T. Kaneko, K. Matsunaga, C. Abetz and V. Abetz, Soft Matter, 2009, 5, 2042.

10 D. B. Amabilino, Chirality at the Nanoscale, VCH-Wiley Weinheim, 2009.

11 D. R. Link, G. Natale, R. Shao, J. E. Maclennan, N. A. Clark, E. Körblova and D. M. Walba, Science, 1997, 278, 1924.

12 E. A. Matsumoto, G. P. Alexander and R. D. Kamien, Phys. Rev. Lett., 2009, 103, 257804.

13 (a) G. Dantlgraber, A. Eremin, S. Diele, A. Hauser, H. Kresse, G. Pelzl and C. Tschierske, Angew. Chem., Int. Ed., 2002, 41, 2408; (b) G. Dantlgraber, S. Diele and C. Tschierske, Chem. Commun., 2002, 2768; (c) C. Tschierske and G. Dantlgraber, Pramana, 2003, 61, 455; (d) C. Keith, R. A. Reddy, A. Hauser, U. Baumeister and C. Tschierske, J. Am. Chem. Soc., 2006, 128, 3051; (e) C. Keith, R. A. Reddy, U. Baumeister, H. Hahn, H. Lang and C. Tschierske, J. Mater. Chem., 2006, 16, 3444; (f) H. Hahn, C. Keith, 
H. Lang, R. A. Reddy and C. Tschierske, Adv. Mater., 2006, 18, 2629; $(g)$ C. Keith, G. Dantlgraber, R. A. Reddy, U. Baumeister, M. Prehm, H. Hahn, H. Lag and C. Tschierske, J. Mater. Chem., 2007, 17, 3796; (h) C. Keith, G. Dantlgraber, R. A. Reddy, U. Baumeister and C. Tschierske, Chem. Mater., 2007, 19, 694; (i) Y. Zhang, U. Baumeister, C. Tschierske, M. O'Callaghan and C. Walker, Chem. Mater., 2010, 22, 2869.

14 L. E. Hough, M. Spannuth, M. Nakata, D. A. Coleman, C. D. Jones, G. Dantlgraber, C. Tschierske, J. Watanabe, E. Körblova, D. M. Walba, J. E. Maclennan, M. A. Glaser and N. A. Clark, Science, 2009, 325, 452.

15 G. Heppke, D. D. Parghi and H. Sawade, Liq. Cryst., 2000, 27, 313.

16 J. Thisayukta, Y. Nakayama, S. Kawauchi, H. Takezoe and J. Watanabe, J. Am. Chem. Soc., 2000, 122, 7441.

17 R. A. Reddy and B. K. Sadashiva, Liq. Cryst., 2003, 30, 1031. 18 A. Roy, M. Gupta, S. Radhika, B. K. Sadashiva and R. Pratibha, Soft Matter, 2012, 8, 7207.

19 J. Ortega, C. L. Folcia, J. Etxebarria, N. Gimeno and M. B. Ros, Phys. Rev. E: Stat., Nonlinear, Soft Matter Phys., 2003, 68, 11707.

20 T. Niori, T. Sekine, J. Watanabe, T. Furukawa and H. Takezoe, J. Mater. Chem., 1996, 6, 1231.

21 J. M. Perdiguero, I. Alonso, C. L. Folcia, J. Etxebarria and J. Ortega, J. Mater. Chem., 2009, 19, 5161.

22 C. Zhang, N. Diorio, O. D. Lavrentovich and A. Jákli, Nat. Commun., 2014, 5, 3302.

23 (a) A. Jákli, Y.-M. Huang, K. Fodor-Csorba, A. Vajda, G. Galli, S. Diele and G. Pelzl, Adv. Mater., 2003, 15, 1606; (b) W. Weissflog, M. W. Schröder, S. Diele and G. Pelzl, Adv. Mater., 2003, 15, 630.

24 (a) L. E. Hough, H. T. Jung, D. Kröuerke, M. S. Heberling, M. Nakata, C. D. Jones, D. Chen, D. R. Link, J. Zasadzinski, G. Heppke, J. P. Rabe, W. Stocker, E. Körblova, D. M. Walba, M. A. Glaser and N. A. Clark, Science, 2009, 325, 456; (b) D. M. Walba, L. Eshat, E. Körblova and R. K. Shoemaker, Cryst. Growth Des., 2005, 5, 2091; (c) D. Chen, J. E. Maclennan, R. Shao, D. K. Yoon, H. Wang, E. Körblova, D. M. Walba, M. A. Glaser and N. A. Clark, J. Am. Chem. Soc., 2011, 133, 12656.

25 (a) J. Thisayukta, H. Takezoe and J. Watanabe, Jpn. J. Appl. Phys., 2001, 40, 3277; (b) H. Niwano, M. Nakata, J. Thisayukta, D. R. Link, H. Takezoe and J. Watanabe, J. Phys. Chem. B, 2004, 108, 14889; (c) H. Kurosu, M. Kawasaki, M. Hirose, M. Yamada, S. Kang, J. Thisayukta, M. Sone, H. Takezoe and J. Watanabe, J. Phys. Chem. A, 2004, 108, 4674.

26 H. Kresse, J. Saltetnokova, H. Nadasi, W. Weissflog and A. Hauser, Liq. Cryst., 2001, 28, 1017.

27 Biphenyl based dimesogens: (a) E. Bialecka-Florjanczyk, I. Sledzinska, E. Górecka and J. Przedmojski, Liq. Cryst., 2008, 35, 401; (b) A. Zep, M. Salamonczyk, N. Vaupotič, D. Pociecha and E. Gorecka, Chem. Commun., 2013, 49, 3119. 28 (a) H. Ocak, B. Bilgin-Eran, M. Prehm and C. Tschierske, Soft Matter, 2012, 8, 7773; (b) H. Ocak, B. Bilgin-Eran, M. Prehm and C. Tschierske, Soft Matter, 2013, 9, 4590.
29 E. Tsai, J. M. Richardson, E. Körblova, M. Nakata, D. Chen, Y. Shen, R. Shao, N. A. Clark and D. M. Walba, Angew. Chem., Int. Ed., 2013, 52, 5254.

30 G. B. Deepa, S. Radhika, B. K. Sadashiva and R. Pratibha, Phys. Rev. E: Stat., Nonlinear, Soft Matter Phys., 2013, 87, 062508.

31 M. Alaasar, M. Prehm, M. Nagaraj, J. K. Vij and C. Tschierske, Adv. Mater., 2013, 25, 2186.

32 M. Alaasar, M. Prehm, K. May, A. Eremin and C. Tschierske, Adv. Funct. Mater., 2014, 24, 1703.

33 (a) G. Pelzl, A. Eremin, S. Diele, H. Kresse and W. Weissflog, J. Mater. Chem., 2002, 12, 2591; (b) T. Niori, J. Yamamoto and H. Yokoyama, Mol. Cryst. Liq. Cryst., 2004, 409, 475.

34 (a) V. Görtz and J. W. Goodby, Chem. Commun., 2005, 3262; (b) V. Görtz, Liq. Cryst. Today, 2010, 19, 37.

35 More recently helical superstructures, the so-called twist bent nematic phases, were reported for mesogenic dimers with odd-numbered spacers: (a) J. W. Emsley, M. Lelli, A. Lesage and G. R. Luckhurst, J. Phys. Chem. B, 2013, 117, 6547; (b) V. Borshch, Y.-K. Kim, J. Xiang, M. Gao, A. J. ákli, V. P. Panov, J. K. Vij, C. T. Imrie, M. G. Tamba, G. H. Mehl and O. D. Lavrentovich, Nat. Commun., 2013, 4, 2635; (c) D. Chen, J. H. Porada, J. B. Hooper, A. Klittnick, Y. Shen, M. R. Tuchband, E. Körblova, D. Bedrov, D. M. Walba, M. A. Glaser, J. E. Maclennan and N. A. Clark, Proc. Natl. Acad. Sci. U. S. A., 2013, 110, 15931.

36 (a) D. K. Yoon, Y. Yi, Y. Shen, E. D. Körblova, D. M. Walba, I. I. Smalyukh and N. A. Clark, Adv. Mater., 2011, 23, 1962; (b) D. Chen, C. Zhu, H. Wang, J. E. Maclennan, M. A. Glaser, E. Körblova, D. M. Walba, J. A. Rego, E. A. S. Bustamante and N. A. Clark, Soft Matter, 2013, 9, 462.

37 E. Peeters, J. Lub, J. A. M. Steebakkers and D. J. Broer, Adv. Mater., 2006, 18, 2412.

38 (a) I. C. Pintre, J. L. Serrano, M. B. Ros, J. M. Perdiguero, I. Alonso, J. Ortega, C. L. Folcia, J. Etxebarria, R. Alicante and B. Villacampa, J. Mater. Chem., 2010, 20, 2965; (b) C. L. Folcia, I. Alonso, J. Etxebarria, I. Pintre and M. B. Ros, Chem. Mater., 2006, 18, 4617.

39 G. Lee, R. J. Carlton, F. Araoka, N. L. Abbott and H. Takezoe, Adv. Mater., 2013, 25, 245.

40 T. Ueda, S. Masuko, F. Araoka, K. Ishikawa and H. Takezoe, Angew. Chem., 2013, 125, 7001.

41 Dimesogen azobenzene: (a) S.-W. Choi, T. Izumi, Y. Hoshino, Y. Takanishi, K. Ishikawa, J. Watanabe and H. Takezoe, Angew. Chem., Int. Ed., 2006, 45, 1382; (b) G. Lee, R. J. Carlton, F. Araoka, N. L. Abbott and H. Takezoe, Adv. Mater., 2013, 25, 245; (c) A. Zep, K. Sitkowska, D. Pociecha and E. Gorecka, J. Mater. Chem. C, 2014, 2, 2323.

42 I. Miyake, Y. Takanishi, N. V. S. Rao, M. K. Paul, K. Ishikawa and H. Takezoe, J. Mater. Chem., 2005, 15, 4688.

43 M. Alaasar, M. Prehm and C. Tschierske, Chem. Commun., 2013, 49, 11062.

44 M. Alaasar, M. Prehm, M. Brautzsch and C. Tschierske, J. Mater. Chem. C, 2014, 2, 5487.

45 There are numerous different effects of the F-substituents at the aromatic core, which influence each other and hence 
specific effects are difficult to distinguish. Firstly, due to their slightly larger size compared to that of hydrogen, fluorine substituents change the steric intermolecular interactions and also have effects on the conformation of the adjacent alkyl chains. Secondly, fluorine has a strong influence on the intermolecular interactions as a result of its electronegative character, which affects the electron density of the aromatic ring leading to changes in the $\pi-\pi$ stacking and $\pi \cdots \mathrm{H}-\mathrm{C}$ electrostatic interactions between the aromatic rings, (M. O. Sinnokrot and C. D. Sherrill, J. Am. Chem. Soc., 2004, 126, 7690) as well as the polarization, surface charge distribution and polarizability of the whole conjugated $\pi$-system.

46 R. A. Reddy, V. A. Raghunathan and B. K. Sadashiva, Chem. Mater., 2005, 17, 274.

47 M. Alaasar, M. Prehm and C. Tschierske, Liq. Cryst., 2013, 40, 656.

48 I. Niezgoda, D. Pociecha and Z. Galewski, Thermochim. Acta, 2014, 587, 59.

49 M. Alaasar, M. Prehm and C. Tschierske, Liq. Cryst., 2014, 41, 126.

50 A. Guinier, X-ray Diffraction, Freeman, San Francisco, 1963.

51 T. Otani, F. Araoka, K. Ishikawa and H. Takezoe, J. Am. Chem. Soc., 2009, 131, 12368; F. Araoka, G. Sugiyama, K. Ishikawa and H. Takezoe, Opt. Mater. Express, 2011, 1, 27.
52 N. G. Nagaveni, A. Roy and V. Prasad, J. Mater. Chem., 2012, 22, 8948.

53 A. Immirzi and B. Perini, Acta Crystallogr., Sect. A: Cryst. Phys., Diffr., Theor. Gen. Crystallogr., 1977, 33, 216.

54 D. R. Lide, CRC Handbook of Chemistry and Physics, Internet Version, 2005, http://www.hbcpnetbase.com.

55 M. J. Frisch et al., Gaussian 09, Revision A.1, Gaussian Inc., Wallingford CT, 2009.

56 (a) I. Wirth, S. Diele, A. Eremin, G. Pelzl, S. Grande, L. Kovalenko, N. Pancenko and W. Weissflog, J. Mater. Chem., 2001, 11, 1642; (b) L. Kövalenko, M. W. Schröder, R. A. Reddy, S. Diele, G. Pelzl and W. Weissflog, Liq. Cryst., 2005, 32, 857.

57 In contrast to the rigid resorcinol based bent-core mesogens, reported here, the azobenzene based dimesogens form HNF type DC phases, ${ }^{27}$ presumably because in this case the inherent bent of the odd-numbered alkylene space provides helical conformational chirality, and because this kind of spacer is "softer" these molecules can still adopt helical nanofilaments even in the presence of the rigid azobenzene units.

58 Z. Fang and C. Cao, J. Mol. Struct., 2013, 1036, 447.

59 H. G. Heller and J. R. Langan, J. Chem. Soc., Perkin Trans. 2, $1981,341$.

60 P. Schmitz, H. Gruler and M. Eberhardt, Mol. Cryst. Liq. Cryst., 1995, 262, 129. 